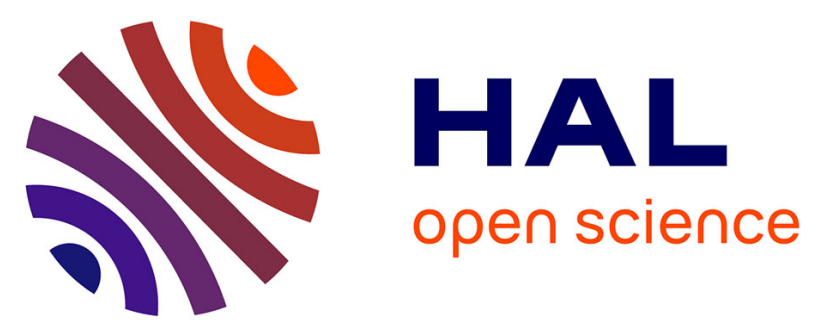

\title{
Mechanisms explaining the role of viscosity and post-deglutitive pharyngeal residue on in vivo aroma release: A combined experimental and modeling study
}

Marion M. Doyennette, Clément C. de Loubens de Verdalle, Isabelle I. Deleris, Isabelle I. Souchon, Ioan-Cristian I.-C. Trelea

\section{To cite this version:}

Marion M. Doyennette, Clément C. de Loubens de Verdalle, Isabelle I. Deleris, Isabelle I. Souchon, Ioan-Cristian I.-C. Trelea. Mechanisms explaining the role of viscosity and post-deglutitive pharyngeal residue on in vivo aroma release: A combined experimental and modeling study. Food Chemistry, 2011, 128 (2), pp.380 - 390. 10.1016/j.foodchem.2011.03.039 . hal-01000976

\section{HAL Id: hal-01000976 https://hal.science/hal-01000976}

Submitted on 12 Jul 2017

HAL is a multi-disciplinary open access archive for the deposit and dissemination of scientific research documents, whether they are published or not. The documents may come from teaching and research institutions in France or abroad, or from public or private research centers.
L'archive ouverte pluridisciplinaire HAL, est destinée au dépôt et à la diffusion de documents scientifiques de niveau recherche, publiés ou non, émanant des établissements d'enseignement et de recherche français ou étrangers, des laboratoires publics ou privés. 

Mechanisms explaining the role of viscosity and post3 deglutitive pharyngeal residue on in vivo aroma release: a

\section{combined experimental and modeling study}

${ }^{1}$ UMR 782 Génie et Microbiologie des Procédés Alimentaires, INRA/AgroParisTech, CBAI 7 78850 Thiverval Grignon, France 


\section{Abstract}

13 The objective of this study was to analyze the viscosity effect of liquid Newtonian products on aroma

14 release, taking human physiological characteristics into account. In vivo release of diacetyl from

15 glucose syrup solutions varying widely in viscosity (from 0.7 to $405 \mathrm{mPa}$ ) was assessed by five

16 panelists using Proton Transfer Reaction Mass Spectrometry (PTR-MS). The physicochemical

17 properties of the solutions and the physiological parameters of subjects were experimentally measured.

18 In parallel, a mechanistic model describing aroma release while eating a liquid food was developed.

19 Model predictions based on the characteristics of the glucose syrup solution were invalidated when

20 compared to in vivo measurements. Therefore, the assumption that the post-deglutitive pharyngeal

21 residue was considerably diluted with saliva was introduced into the model. Under this hypothesis, the

22 model gives a satisfactory prediction of the in vivo data. Thus, relevant properties to be considered for

23 in vivo release were those of product-saliva mixes.

26 Keywords: Flavor release; saliva dilution; swallowing; dynamic modeling; rheology. 
 \\ 1. Introduction}

Aroma compound release and perception determine the aromatic quality of food products and contribute to consumer choices and preferences. During consumption, flavor delivery is particularly determined by product properties (structure and composition) and individual physiology. Understanding the key mechanisms of release is of great practical interest for rational food design and formulation (Linforth \& Taylor, 2000).

In the present work, the focus has been placed on the effect of matrix viscosity. This subject has already been discussed in the literature but there appears to be no consensus. On the one hand, some authors observed no effect of product viscosity on aroma release kinetics (Cook, Hollowood, Linforth \& Taylor, 2003; Hollowood, Linforth \& Taylor, 2002; Weel, Boelrijk, Burger, Verschueren, Gruppen, Voragen et al., 2004). These authors studied solutions viscosified with hydrocolloids. Their analysis may have been biased by the fact that the concentration of the viscosifying agent modified both rheological and physico-chemical properties. On the other hand, some authors found an impact of viscosity on aroma release (Saint-Eve, Martin, Guillemin, Semon, Guichard \& Souchon, 2006). They obtained different rheological properties by a mechanical treatment that does not modify the product composition and that therefore leaves physico-chemical properties such as air/product partition coefficients unchanged (Kora, Souchon, Latrille, Martin \& Marin, 2004). In that way, authors were able to uncouple rheological and physico-chemical properties in their study. Saint-Eve et al. (2006) showed a strong influence of yogurt complex viscosity on aroma release and hypothesized that these differences were due to different mechanical behaviors of the products in the mouth or in the pharynx. However, yogurts present complex rheological properties such as viscoelasticity and yield stress. These complex behaviors, leading to different experimental conditions when compared with the other studies, could explain the conflicting results.

In this context, the objective of this study was to analyze the Newtonian viscosity effects on the aroma release kinetics of the products. To this end, we measured in vivo aroma release kinetics by Proton Transfer Reaction Mass Spectrometry (PTR-MS) after the ingestion of glucose syrup solutions. These solutions were Newtonian liquids for which a wide range of viscosities could be obtained. 
Increasing the carbohydrate concentration of the solutions increased the Newtonian viscosity but modified the air/product partition and mass transfer coefficients as well. In order to quantify these effects independently, we developed a mechanistic model that described aroma release during consumption of a liquid and semi-liquid food. Most of the model parameters related to the products or to the subjects were measured experimentally. Comparing the model predictions under different assumptions with the experimental data allowed us to understand the influence of viscosity on aroma release.

The mechanistic model describing aroma release in the present study was developed on the basis of the work described by Trelea, Atlan, Deleris, Saint-Eve, Marin \& Souchon (2008). The sensitivity analysis of the previous model highlighted the parameters that have a major influence on aroma release kinetics. For example, the residual product layer thickness reduction in the pharynx accelerates the volatile compound depletion by the breath flow rate, whereas its increase induces a longer persistence effect. The breath flow rate also influences the aromatic persistence. In addition, increasing the equilibrium partition coefficient or the mass transfer coefficient increases the aroma concentration in the nasal cavity.

Most of these key parameters can be determined experimentally or evaluated from the literature. However, the residual thickness of a product is an unknown parameter that should depend both on the product viscosity and on the individual physiology. Due to the presence of saliva on the pharyngeal mucosa, two hypotheses can be formulated about the nature of this post-deglutitive pharyngeal residue. The first one considers that the initial saliva thickness in the pharynx is very thin compared to the deposited thickness of the product, or is swept out during swallowing: a pure product layer coats the mucosa. In the second hypothesis, we consider that the amount of saliva on the mucosa is large: the deposited residue layer is a mix of saliva and the product.

These two assumptions were tested successively. In order to do this, the present work was carried out in successive steps. First, a model of aroma release during ingestion was developed. In parallel, relevant physico-chemical and physiological parameters were measured using in vitro or in vivo experiments, or were calculated from the literature or experimental data. Finally, model predictions under the two hypotheses were compared to measured in vivo release data. 
Nomenclature

\begin{tabular}{|c|c|c|}
\hline Symbol & Unit & Parameter \\
\hline $\mathrm{A}_{\mathrm{FAP}}$ & $\mathrm{cm}^{2}$ & Air/product contact area in the pharynx \\
\hline $\mathrm{A}_{\mathrm{OAP}}$ & $\mathrm{cm}^{2}$ & Air/product contact area in the oral cavity \\
\hline $\mathrm{C}_{\mathrm{FA}}$ & $\mathrm{g} / \mathrm{cm}^{3}$ & Aroma concentration present in the air in the pharynx \\
\hline $\mathrm{C}_{\mathrm{FP}}$ & $\mathrm{g} / \mathrm{cm}^{3}$ & Aroma concentration present in the product in the pharynx \\
\hline $\mathrm{C}_{\mathrm{FP}}^{*}$ & $\mathrm{~g} / \mathrm{cm}^{3}$ & Aroma concentration present at the air/product interface in the pharynx \\
\hline $\mathrm{C}_{\mathrm{NA}}$ & $\mathrm{g} / \mathrm{cm}^{3}$ & Aroma concentration present in the air in the nasal cavity \\
\hline $\mathrm{C}_{\mathrm{OA}}$ & $\mathrm{g} / \mathrm{cm}^{3}$ & Aroma concentration present in the air in the oral cavity \\
\hline $\mathrm{C}_{\mathrm{OP}}$ & $\mathrm{g} / \mathrm{cm}^{3}$ & Aroma concentration present in the product in the oral cavity \\
\hline $\mathrm{C}_{\mathrm{OP}}^{*}$ & $\mathrm{~g} / \mathrm{cm}^{3}$ & Aroma concentration present at the air/product interface in the oral cavity \\
\hline $\mathrm{e}$ & $\mu \mathrm{m}$ & Residual product layer thickness \\
\hline $\mathrm{F}_{\mathrm{R}}$ & Number of cycles/s & Respiratory frequency \\
\hline $\mathrm{K}_{\mathrm{AP}}$ & & Air/product partition coefficient \\
\hline $\mathrm{k}_{\mathrm{P}}$ & $\mathrm{m} / \mathrm{s}$ & Mass transfer coefficient in the product layer \\
\hline$t_{\text {deg }}$ & & Swallowing moment \\
\hline $\mathrm{Q}_{\mathrm{NA}}$ & $\mathrm{cm}^{3} / \mathrm{s}$ & Respiratory flow rate \\
\hline $\mathrm{QS}_{\mathrm{S}}$ & $\mathrm{cm}^{3} / \mathrm{s}$ & Salivary flow rate \\
\hline $\mathrm{V}_{\mathrm{FA}}$ & $\mathrm{cm}^{3}$ & Volume of air in the pharynx \\
\hline $\mathrm{V}_{\mathrm{FP}}$ & $\mathrm{cm}^{3}$ & Volume of the product in the pharynx \\
\hline $\mathrm{V}_{\text {lung }}$ & $\mathrm{cm}^{3}$ & Lung volume \\
\hline $\mathrm{V}_{\mathrm{NA}}$ & $\mathrm{cm}^{3}$ & Volume of air in the nasal cavity \\
\hline $\mathrm{V}_{\mathrm{OA}}$ & $\mathrm{cm}^{3}$ & Volume of air in the oral cavity \\
\hline $\mathrm{V}_{\mathrm{OP}}$ & $\mathrm{cm}^{3}$ & Volume of product in the oral cavity \\
\hline $\mathrm{V}_{\text {OPres }}$ & $\mathrm{cm}^{3}$ & Volume of residual product in the oral cavity \\
\hline $\mathrm{V}_{\mathrm{T}}$ & $\mathrm{cm}^{3}$ & Tidal volume \\
\hline
\end{tabular}




\begin{tabular}{|l|l|l|}
\hline$\phi_{\mathrm{FPA}}$ & $\mathrm{g} / \mathrm{s}$ & Volatile mass flux between the product and the air in the pharynx \\
\hline$\phi_{\mathrm{OPA}}$ & $\mathrm{g} / \mathrm{s}$ & Volatile mass flux between the product and the air in the oral cavity \\
\hline$\tau$ & $\mathrm{s}$ & Characteristic time of the aroma release decay \\
\hline
\end{tabular}

86

87

88

89

90

\section{Material and Methods}

\subsection{Mathematical model for in vivo release}

\subsubsection{Principle of the model}

A model describing aroma compound release during liquid and semi-liquid food consumption was previously developed by Trelea et al. (2008). It is based on a physiological representation of the deglutition process as described by Buettner, Beer, Hannig \& Settles (2001). A schematic representation of the various compartments involved in the modeling design, as well as their connections, is given in Fig. 1A. We considered that the oral cavity (index O), the pharynx (index F) and the nasal cavity (index N) were interconnected compartments containing product and/or air phase. In the present study, two main simplifications were performed with the aim of eliminating parameters that have little impact on model predictions and which are difficult to determine experimentally.

The first simplification concerns the number of swallowing steps. In the original model, the product consumption process was decomposed into a series of four steps. Three of them concerned the deglutition event. However, they were very short and quite difficult to validate experimentally. Therefore, the new version of the model considers only three steps: product residence in the mouth, swallowing and release after swallowing. The swallowing step includes simultaneous contraction of the oral cavity and of the pharynx, leading to air and product expulsion, followed by relaxation and filling with fresh air. Figure 1B shows the successive steps modeled in the present work. 
108 The second simplification of the model consisted in neglecting the aroma compound transfer

109 resistance in the air at the gas/product interface compared to the resistance in the product.

110 After these model simplifications, the number of physicochemical and physiological parameters that

111 needs to be known is reduced from 24 to 16 . A comparison of the new model with the previous one

112 shows that these simplifications do not change the predictions in any significant way.

113 Therefore, the model simulates the relative concentration of a specific aroma compound in the nose

114 space of the subject. Aroma compound concentrations in all compartments (oral cavity, pharynx and

115 nasal cavity) were calculated using mass transfer equations and mass balances. Isothermal conditions

116 were assumed. Moreover, aroma compounds have a strong preference for the aqueous phase compared

117 to the air, and the contact area between air and lungs is very large $\left(\sim 100 \mathrm{~m}^{2}\right)$ (Menache, Hanna, Gross,

118 Lou, Zinreich, Leopold et al., 1997). Thus, it seems reasonable to assume that aroma compounds are

119 quickly absorbed into the lungs. It was therefore assumed that the air coming from the trachea (i.e., the

120 lungs) would be aroma-free. If we take a closer look at the anatomy of the nose, we can subdivide the

121 nasal cavity into the nasal vestibule, the anterior turbinate and the posterior turbinate with different

122 volumes and airflow rates (Wen, Inthavong, Tu \& Wang, 2008). Similarly, it could be possible to take

123 aroma compound-mucosa interactions into account. These additional phenomena were tentatively

124 incorporated into a provisional model but were not retained in the final model, as will be explained

125 below in the Results and Discussion section.

126 Moreover, concerning the presence of saliva on the pharyngeal mucosa, two different hypotheses 127 about the nature of the bolus that coats the pharyngeal mucosa after swallowing were considered. The 128 first one (H1) assumes that a pure product layer is deposited on the pharyngeal mucosa. The second 129 one (H2) assumes that the product coating the pharyngeal mucosa is significantly diluted with saliva.

130 In that case, contrarily to the first hypothesis, the physico-chemical parameters of the bolus have to be 131 recalculated on the basis of the dilution rate. 
135 We refer to the time of product introduction in mouth and the time of deglutition as $t_{0}$ and $t_{\text {deg }}$,

136 respectively.

138 Step 1: product residence in the mouth

$139 \checkmark$ Product in the oral cavity

140 The mouth is closed during this step and does not exchange aroma compounds with other

141 compartments. The volume of the product in the oral cavity $\mathrm{V}_{\text {op }}$ increases due to dilution by saliva.

$$
\frac{d V_{O P}(t)}{d t}=Q_{S}
$$

143 The volatile mass flux $\phi_{\mathrm{OPA}}$ is given by the difference between the product concentration $\left(\mathrm{C}_{\mathrm{OP}}\right)$ and the

144 interfacial concentration $\left(\mathrm{C}^{*}{ }_{\mathrm{OP}}\right)$ :

$$
\phi_{O P A}(t)=A_{O A P} \times k_{P} \times\left(C_{O P}(t)-C_{O P}^{*}(t)\right)
$$

146 where $k_{P}$ is the mass transfer coefficient of the aroma compound in the product.

147 The variation of the aroma concentration present in the product $\mathrm{C}_{\mathrm{OP}}$ is due to release to the air in the 148 mouth (transfer through the product-air interface $\mathrm{A}_{\mathrm{OAP}}$ ) and to dilution by saliva flow $\mathrm{Q}_{\mathrm{S}}$ :

$$
V_{O P}(t) \times \frac{d C_{O P}(t)}{d t}=-\phi_{O P A}(t)-Q_{S} \times C_{O P}(t)
$$

\section{$\checkmark$ Air in the oral cavity}

152 The variation of aroma concentration in the air $\mathrm{C}_{\mathrm{OA}}$ is due to the volatile flux from the product in the 153 mouth $\phi_{\mathrm{OPA}}$ :

$$
V_{O A} \times \frac{d C_{O A}(t)}{d t}=\phi_{O P A}(t)
$$

\section{$\checkmark$ Interfacial conditions}

157 The interfacial aroma compound concentration on the product side was calculated using the partition

158 conditions at the interface (Cussler, 1997). Since transfer resistance on the air side was assumed to be

159 negligible, the interfacial air concentration is the same as the bulk air concentration: 


$$
K_{A P}=\frac{C_{O A}(t)}{C_{O P}^{*}(t)}
$$

161 where $\mathrm{K}_{\mathrm{AP}}$ is the air/product partition coefficient.

162

163 Initial conditions for Step 1: product residence in the mouth

164 At the beginning of Step 1, the product introduced into the mouth $\left(\mathrm{C}_{\mathrm{OPini}}\right)$ is the only compartment 165 containing aroma compounds. Hence, the initial conditions are:

$$
\mathrm{C}_{\mathrm{OP}}\left(\mathrm{t}_{0}\right)=\mathrm{C}_{\mathrm{OPini}}
$$

$$
\mathrm{C}_{\mathrm{OA}}\left(\mathrm{t}_{0}\right)=\mathrm{C}_{\mathrm{FP}}\left(\mathrm{t}_{0}\right)=\mathrm{C}_{\mathrm{FA}}\left(\mathrm{t}_{0}\right)=\mathrm{C}_{\mathrm{NA}}\left(\mathrm{t}_{0}\right)=0
$$

Step 2: Swallowing

The deglutition step is very short compared to the mouth residence step. The main modeling

171 implication is that the transfer to the gaseous phase is negligible during deglutition.

172 To describe this sequence of very quick contraction and relaxation events, the following notation is 173 used (Fig. 1B):

- $t_{\text {deg- }}$ corresponds to the product and air status immediately before the oral and pharyngeal contraction begins. It is the end of Step 1;

- $t_{\text {deg }}$ corresponds to the status between the end of the contraction and the subsequent relaxation of the pharynx and mouth;

- $t_{\text {deg+ }}$ corresponds to the moment just after pharynx and mouth relaxation. This is the end of Step 2 and the beginning of Step 3.

180

\section{$\checkmark$ Product in the oral cavity}

182 After the oral cavity contraction, the residual amount of product is assumed to be equal to the usual

183 residual amount of saliva:

$$
V_{O P}\left(t_{\mathrm{deg}}\right)=V_{O \text { Pres }}
$$


185 Since Step 2 is very short, the aroma compound concentration in the oral cavity is unchanged during

186 deglutition (negligible dilution by saliva and transfer to air):

$$
C_{O P}\left(t_{\mathrm{deg}+}\right)=C_{O P}\left(t_{\mathrm{deg}}\right)=C_{O P}\left(t_{\mathrm{deg}-}\right)
$$

\section{$\checkmark$ Product in the pharynx}

190 During deglutition, it is assumed under hypothesis (H1) that the saliva film in the pharynx is swept out

191 by the large amount of product coming from the mouth:

$$
C_{F P}\left(t_{\text {deg }+}\right)=C_{O P}\left(t_{\text {deg- }}\right)
$$

\section{Step 3: Release after swallowing}

The initial conditions of Step 3 are the final values of Step 2 (at $\left.t_{\text {deg+ }}\right)$.

\section{$\checkmark$ Air in nasal cavity, pharynx and mouth} total mass divided by the total volume:

$$
C_{N A}\left(t_{\mathrm{deg}}\right)=\frac{V_{O A} \times C_{O A}\left(t_{\mathrm{deg}-}\right)+V_{F A} \times C_{F A}\left(t_{\mathrm{deg}-}\right)+V_{N A} \times C_{N A}\left(t_{\mathrm{deg}-}\right)}{V_{O A}+V_{F A}+V_{N A}}
$$
concentrations will be:

$$
C_{N A}\left(t_{\mathrm{deg}+}\right)=C_{F A}\left(t_{\mathrm{deg}+}\right)=C_{O A}\left(t_{\mathrm{deg}+}\right)=\frac{V_{N A} \times C_{N A}\left(t_{\mathrm{deg}}\right)}{V_{O A}+V_{F A}+V_{N A}}
$$
the saliva film in the pharynx. This corresponds to the dilution factor discussed below.

Assuming that during the contraction, the expelled air is well mixed in the mouth, pharynx and nose, the intermediate aroma compound concentration in the nasal cavity, after contraction, is given by the

After the contraction, the amount of aroma compound present in the upper airway is $V_{N A} \times C_{N A}\left(t_{\mathrm{deg}}\right)$. After relaxation, this amount is diluted by ambient air. Assuming good mixing, the final

\section{$\checkmark$ Product in the pharynx}


210 The residual product in the pharynx releases aroma compounds into the adjacent air. The volatile flux

$211 \phi_{\mathrm{FPA}}$ is given by:

$$
\phi_{F P A}(t)=A_{F A P} \times k_{P} \times\left(C_{F P}(t)-C_{F P}^{*}(t)\right)
$$

213 The mass balance of the aroma compound in the product layer gives:

$$
V_{F P} \times \frac{d C_{F P}(t)}{d t}=-\phi_{F P A}(t)
$$

The product volume in the pharynx $\mathrm{V}_{\mathrm{FP}}$ can be expressed as the product of the residual layer thickness $e$ and the pharynx area $A_{F A P}$, i.e. $V_{F P}=A_{F A P} \times e$. The previous equation can be further simplified to:

$$
\frac{d C_{F P}(t)}{d t}=-\frac{k_{p}}{e} \times\left(C_{F P}(t)-C_{F P}^{*}(t)\right)
$$

\section{$\checkmark$ Air in the pharynx}

220 The air in the pharynx exchanges aroma compounds with the residual product coating the pharynx walls and with the airflow $\mathrm{Q}_{\mathrm{NA}}$ from the nasal cavity (inhalation) or the lungs (expiration).

$$
V_{F A} \times \frac{d C_{F A}(t)}{d t}=\phi_{F P A}(t)+\left\{\begin{array}{clll}
Q_{N A}(t) \times\left(C_{N A}(t)-C_{F A}(t)\right) & \text { if } & \mathrm{Q}_{\mathrm{NA}}(\mathrm{t}) \geq 0 & \text { (inhalation) } \\
-Q_{N A}(t) \times\left(0-C_{F A}(t)\right) & \text { if } \quad \mathrm{Q}_{\mathrm{NA}}(\mathrm{t})<0 & \text { (expiration) }
\end{array}\right.
$$

\section{Air in the nasal cavity}

The concentration of aroma compounds in the nasal cavity results from a dilution with the ambient air during inhalation and with air coming from the pharynx during expiration:

$$
V_{N A} \times \frac{d C_{N A}(t)}{d t}=\left\{\begin{array}{clll}
Q_{N A}(t) \times\left(0-C_{N A}(t)\right) & \text { if } & \mathrm{Q}_{\mathrm{NA}}(\mathrm{t}) \geq 0 & \text { (inhalation) } \\
-Q_{N A}(t) \times\left(C_{F A}(t)-C_{N A}(t)\right) & \text { if } & \mathrm{Q}_{\mathrm{NA}}(\mathrm{t})<0 & \text { (expiration) }
\end{array}\right.
$$

\section{$\checkmark$ Interfacial conditions}

Similarly to what happens in the oral cavity (Equation (5)), the interfacial air concentration in the pharynx is the same as the bulk air concentration: 


$$
K_{A P}=\frac{C_{F A}(t)}{C_{F P}^{*}(t)}
$$

\section{$\checkmark$ Calculation of the respiratory flow rate}

235 We based our calculation of the airflow rate $\mathrm{Q}_{\mathrm{NA}}$ on the assumption that the volume of air inhaled and 236 exhaled by the panelist had a sinusoidal shape. The tidal volume $V_{T}$ and the respiratory frequency $F_{R}$ 237 were required for this calculation (Section 2.6 for details about this data acquisition).

238 The time shift $\left(t-t_{\text {deg }}\right)$ was introduced to ensure that the deglutition event is always followed by expiration, as physiologically observed. This is referred to as a swallow breath.

240 Assuming that lung volume variation is as follows:

$$
V_{\text {lung }}(t)=\text { const }+\frac{V_{T}}{2} \times \cos \left(\pi \times 2 \times F_{R} \times\left(t-t_{\text {deg }}\right)\right)
$$

where the constant accounts for the average air volume in the lungs, the expression of $\mathrm{Q}_{\mathrm{NA}}$ will be:

$$
Q_{N A}(t)=\frac{d V_{\text {lung }}(t)}{d t}=-\pi \times F_{R} \times V_{T} \times \sin \left(\pi \times 2 \times F_{R} \times\left(t-t_{\text {deg }}\right)\right)
$$

\subsubsection{Model parameters}

247 Model parameters can be related to the product, the consumer or the interaction between them.

248 1. Parameters related to the product

249 These parameters include the initial aroma compound concentration, the air/product partition 250 coefficient and the mass transfer coefficient. The first parameter above is directly calculated from the 251 product flavoring protocol (Section 2.2), and the second one is estimated via the non linear phase ratio 252 variation method described in Atlan, Trelea, Saint-Eve, Souchon \& Latrille (2006). The mass transfer 253 coefficient was measured with the headspace method (Lauverjat, de Loubens, Deleris, Trelea \& 254 Souchon, 2009). Experimental protocols are described in detail in Section 2.4. 
These parameters include the areas and volumes of the various compartments of the oro-nasalpharyngeal sphere, as well as the saliva and airflow rates. Data collection protocols are described in detail in the Section 2.6.

3. Parameters related to product-consumer interaction

These parameters are the residual amounts of the product and the air/product contact areas (both in the mouth and in the pharynx). Residual product left in the mouth after swallowing was arbitrarily set to

$2621 \%$ of the initial volume of product in the oral cavity. The air/product contact areas of the mouth and 263 pharynx were calculated as detailed in Appendix A. The thickness of the post-deglutitive pharyngeal 264 residue coating the pharynx was the degree of freedom of the model. Since it only affected the part of 265 the curve related to the persistence of aroma, it was determined so that the model fitted the decay time 266 of the experimental curve for each panelist, product and replicate.

267 The effects of these parameters on model prediction were investigated and are presented in the 268 "Results and Discussion" section.

\subsection{Preparation of flavored products}

272 Seven solutions were prepared with a glucose syrup (C*Sweet M01623, Cerestar, Europe) and mineral water (Evian). The dry matters of final solutions varied from $0 \mathrm{~g} / 100 \mathrm{~g}$ to $70 \mathrm{~g} / 100 \mathrm{~g}$. All preparations presented a Newtonian behavior, i.e., viscosity was constant regardless of the shearing rate applied.

275 Viscosities were measured with Physica MCR301 rheometer (Anton Paar Germany GmbH, Ostfildern, 276 Germany) and were between 0.7 and $405 \mathrm{mPa} \mathrm{s}$ at $35^{\circ} \mathrm{C}$. The characteristics of the solutions are 277 summarized in Table 1. The solutions investigated in this paper were labeled according to their 278 approximate percentage of dry matter (for example, G60 had a dry matter of $61.11 \mathrm{~g} / 100 \mathrm{~g}$ ). These solutions were flavored with diacetyl and ethyl hexanoate, which had been previously dissolved in $99.46 \%$ of propylene glycol (Aldrich, France). Final concentrations of diacetyl and ethyl hexanoate in

281 the solutions studied were approximately $20 \mathrm{mg} / \mathrm{L}$ and $88 \mathrm{mg} / \mathrm{L}$, respectively, for the in vivo 282 experiments, $140 \mathrm{mg} / \mathrm{L}$ and $8.3 \mathrm{mg} / \mathrm{L}$, respectively, for the in vitro determination of air/product 
partition coefficients, and $1.5 \mathrm{mg} / \mathrm{L}$ and $0.85 \mathrm{mg} / \mathrm{L}$, respectively, for the in vitro determination of mass transfer coefficients.

For the rest of this work, we focused on the diacetyl results. Data concerning ethyl hexanoate will be used for the validation step.

\subsection{Measurement of in vitro and in vivo aroma release by Proton Transfer}

\section{Reaction-Mass Spectrometry}

The dynamic release of aroma compounds for in vitro and in vivo experiments was measured online using a Proton Transfer Reaction Mass Spectrometer (PTR-MS, Ionicon, Innsbruck, Austria).

The PTR-MS inlet was connected to samples or to the subject's nose via a 1/16" PEEK tube maintained at $60^{\circ} \mathrm{C}$. The PTR-MS instrument drift tube was thermally controlled (Tdrift $=60^{\circ} \mathrm{C}$ ) and operated at Pdrift $=200 \mathrm{~Pa}$ with a voltage set of Udrift $=600 \mathrm{~V}$. Measurements were performed with the multiple ion detection mode on specific masses with a dwell time of $50 \mathrm{~ms}$ per mass. Diacetyl was monitored with m/z 87 (molecular ion). For in vivo experiments, $\mathrm{m} / \mathrm{z} 59$ (acetone) was also monitored as a breath marker, as described in Normand, Avison \& Parker (2004) and Trelea et al. (2008).

In addition, masses $\mathrm{m} / \mathrm{z} 21$ (signal for $\mathrm{H}_{3}{ }^{18} \mathrm{O}^{+}$) and $\mathrm{m} / \mathrm{z} 37$ (signal for water clusters $\mathrm{H}_{2} \mathrm{O}-\mathrm{H}_{3} \mathrm{O}^{+}$) were monitored with a dwell time of $100 \mathrm{~ms}$ to check the instrument performances and cluster ion formation. $\mathrm{m} / \mathrm{z} 21$ intensity was $(1.34 \pm 0.51) \times 10^{4} \mathrm{cps}$ for in vitro experiments and $(9.46 \pm 0.035) \mathrm{x}$ $10^{3} \mathrm{cps}$ for in vivo experiments. In both cases, the ratio of intensities of $\mathrm{m} / \mathrm{z} 37$ and 21 variation was lower than $5 \%$. These differences were considered sufficiently small to ensure accurate PTR-MS measurements. For both in vitro and in vivo measurements, a minimum of three replicates were preformed for each condition studied.

Air was sampled from the subject's nose at a flow rate of $35 \mathrm{~cm}^{3} / \mathrm{min}$. Nose space air was sampled via two inlets of a stainless nosepiece placed in both of the assessor's nostrils. 


\subsection{Determination of physicochemical parameters of diacetyl}

\subsubsection{Determination of air/product partition coefficients}

312 The air/product partition coefficient of diacetyl $\mathrm{K}_{\mathrm{AP}}$ was measured for each solution with the Phase

313 Ratio Method using headspace gas chromatography (Ettre, Welter \& Kolb, 1993). A known amount of 314 solution was placed in vials $\left(22.4 \mathrm{~cm}^{3}\right.$, Chromacol, France) and incubated at $35^{\circ} \mathrm{C}$ for 5 hours. After 315 this equilibration time, $2 \mathrm{~cm}^{3}$ of the headspace above the product was sampled and injected with an 316 automatic HS CombiPal sampler (CTC Analytics, Switzerland) into a gas chromatograph HP (GC-FID 317 HP6890, Germany) equipped with an HP-INNOWax polyethylene glycol semi-capillary column J\&W 318 Scientific ( $30 \mathrm{~m} \times 0.53 \mathrm{~mm}$, with a $1 \mu \mathrm{m}$-thick film) and a flame ionization detector. The temperatures 319 of the gas chromatograph injector and detector (GC-FID HP6890, Germany) were both set at $250^{\circ} \mathrm{C}$. 320 The oven program was $12 \mathrm{~min}$ long, starting at $40^{\circ} \mathrm{C}$, for $5^{\circ} \mathrm{C} / \mathrm{min}$ up to $60^{\circ} \mathrm{C}$, then for $10^{\circ} \mathrm{C} / \mathrm{min}$ up to $321120^{\circ} \mathrm{C}$, and $2 \mathrm{~min}$ at $120^{\circ} \mathrm{C}$. The carrier gas was helium (flow rate: $8.4 \mathrm{~cm}^{3} / \mathrm{min}$, corresponding to a 57 $322 \mathrm{~cm} / \mathrm{s}$ average velocity at $50^{\circ} \mathrm{C}$ ). Peak areas were measured using Hewlett-Packard Chemstation 323 integration software.

324 A non-linear regression was performed on the data set as described in Atlan et al. (2006). A minimum 325 of three replicates were performed for each solution tested.

\subsubsection{Determination of mass transfer coefficients}

The method used for mass transfer coefficient measurements was based on two studies: the Static Equilibrium and Headspace Dilution Analysis (Marin, Baek \& Taylor, 1999) and the Volatile Air

331 Stripping Kinetic (VASK) method (Lauverjat, de Loubens, Deleris, Trelea \& Souchon, 2009).

332 Five g of solution were poured into $134.8-\mathrm{cm}^{3}$ vials (three replicates/solution). The samples were left

333 for a minimum of $12 \mathrm{~h}$ at $35^{\circ} \mathrm{C}$ to establish thermodynamic equilibrium. The headspace was then 334 stripped by a gaseous flow at a controlled rate of $1.45 \mathrm{~cm}^{3} / \mathrm{s}$ (Brooks Digital Mass Flow Meter, Brooks Instrument 5860s). The evolution over time of headspace concentration of these vials was measured by PTR-MS for 25 minutes. The experiment time had to be longer than four times the characteristic 
time of the headspace stripping $\frac{V}{Q}$, where $\mathrm{V}$ is the volume of the headspace, and $\mathrm{Q}$ the stripping

338 airflow rate. In fact, when the experiment time is shorter than $\frac{V}{Q}$, the headspace concentration is

339 mainly governed by dilution with the airflow rate and not by the transfer from the product to the air.

340 Fitting the diacetyl release model (Appendix B for detailed equations) to experimental data made it 341 possible to determine the mass transfer coefficient of this aroma compound in the solutions.

\subsection{In-nose measurements of aroma release and data processing}

344 Five panelists (three females and two males, all Caucasian) aged between 25 and 38 years old were 345 recruited for this study. Only the four solutions presenting the widest range of viscosities (G0, G40, $346 \mathrm{G} 60$ and G70) were investigated in vivo. The $10-\mathrm{cm}^{3}$ samples were first left at $35^{\circ} \mathrm{C}$ for 2 hours to 347 allow thermal equilibrium. Panelists were then instructed to pour the sample into their mouth, keep it 348 while they were connecting to the PTR-MS (1-2 seconds) and to then swallow. Subjects had to 349 continue to breathe normally through the nose (and with their mouth closed) for approximately one 350 minute, during which time the nose-space PTR-MS signal was recorded. Each experiment was 351 repeated three times.

352 An additional protocol consumption was applied for G0: panelists had to suck up a mouthful of the 353 headspace vial with a straw, swallow it and continue to breathe normally through the nose.

355 On the basis of data treatment observed in the literature, the aroma release curve is rarely analyzed in 356 its entirety. In the modeling studies of Buffo, Rapp, Krick \& Reineccius (2005) and Linforth et al. 357 (2000) on aroma compound persistence in human breath, analyses were performed on the ratio 358 between the corresponding intensities of the second and the first expirations after swallowing for each 359 subject and each aroma compound investigated. Hodgson, Langridge, Linforth \& Taylor (2005) 360 proceeded differently and calculated the decay exponent of the maximum intensity of the second and 361 subsequent breath peaks plotted against time (setting apart the first aroma release peak). 
362 Figure 2 represents the data processing results of our experimental aroma release kinetics for one

363 panelist and one solution. Each kinetic presented a sinusoidal pattern due to the cyclic shape of the

364 breath. For clarity, we smoothed the breath-by-breath aroma release profiles by plotting a curve

365 linking the maxima of the sinusoids (referred to as the "peak curve" in Fig. 2), including the swallow-

366 breath peak. Then, for each product, each panelist and for the three replicates, a mean curve and an

367 envelope curve were built based on the peak lines. This last one represents the standard deviation of

368 the replicates and, as a result, the intra-individual variability.

369 In order to validate model prediction against experimental measurements, simulated data were also

370 represented as a peak line. For ease of comparison among different release curves, the deglutition

371 event was always synchronized at time zero.

372 In the "Results and Discussion" section, two main characteristics of the curves were analyzed during

373 in vivo/simulation comparison: the intensity of the first peak after swallowing, and the decay time of

374 the curve (which is representative of the aroma persistency and related to the thickness of the post-

375 deglutitive residue in the pharynx).

\subsection{Determination of physiological parameters}

379 Volumes of oral, nasal and pharyngeal cavities were measured with the Eccovision Acoustic 380 Rhinopharyngometer from Eccovision (Sleep Group Solutions, North Miami Beach, FL 33162). The

381 air/product contact areas in the mouth and in the pharynx were calculated for each panelist as

382 described in Appendix A. However, for the air/product contact area in the mouth, we only took $60 \%$ of

383 the calculated value, since we estimated that the brief in-mouth product residence did not allow the

384 subjects to spread the product over the full surface of the mouth before swallowing.

385 The volume of solution introduced into the mouth was fixed by the experimental protocol at $10 \mathrm{~cm}^{3}$,

386 which corresponds to a realistic "mouthful". In-mouth saliva volume was set at $1.1 \mathrm{~cm}^{3}$ based on data 387 from Dawes (2008), and stimulated saliva flow rate was measured for each panelist (under a parafilm stimulation). 
The tidal volume of each panelist was measured with a spirometer (SpeeDyn from Dyn'R group) and

390 the respiratory frequency was calculated from the acetone signal measured by PTRMS during the 391 resting time preceding each experiment.

393 Prior to their participation in the experiments, a written consent was obtained from all participants 394 after a full explanation of the purpose and nature of the study.

\section{Results and Discussion}

\subsection{Experimental data}

\subsubsection{Air/product partition coefficients of diacetyl}

Results from PRV experiments are shown in Table 2. The diacetyl air/product partition coefficient for the pure water at $35^{\circ} \mathrm{C}$ was $1.28 \times 10^{-3}$. This value is quite close to the ones obtained by Bakker, Boudaud \& Harrison $(1998)$ at $37^{\circ} \mathrm{C}$, ranging between $1.16 \times 10^{-3}$ and $1.78 \times 10^{-3}$. Additional values of the diacetyl partition coefficient for pure water can be found in the literature, but mostly for experiments performed at $25^{\circ} \mathrm{C}$ or below. By using the Arrhenius law on data obtained by Atlan et al. (2006), it is possible to calculate an activation energy of $40.7^{\circ} \mathrm{kJ} / \mathrm{mol}$ and to extrapolate a partition coefficient value of $1.18 \times 10^{-3}$ at $35^{\circ} \mathrm{C}$, which is very close to the value found in the present work.

407 We can observe that the air/product partition coefficient increases with the dry matter for values greater than $5 \%$ of dry matter solution. Values range from $0.57 \times 10^{-3}$ for G5 up to $2.5 \times 10^{-3}$ for G70. Most of the data available in the literature are for sucrose. For example, Friel, Linforth \& Taylor

410 (2000) showed a similar trend in the air/product partition coefficient for diacetyl for a variation of 411 sucrose concentrations. These phenomena could be explained by a loss of free water due to hydration 412 of sugar molecules. Increasing the sucrose concentration makes the solvent character of a solution 413 more hydrophobic. Therefore, for a hydrophilic aroma compound such as diacetyl, its affinity for the 
414 product would be reduced (Nahon, Koren, Roozen \& Posthumus, 1998; Nawar, 1971; Thanh, 415 Thibeaudeau, Thibaut \& Voilley, 1992).

\subsubsection{Mass transfer coefficients of diacetyl}

418 The mass transfer coefficients calculated with the headspace dilution method are presented in Table 2.

419 They ranged between $1.1 \times 10^{-6} \mathrm{~m} / \mathrm{s}$ (pure water) and $3.31 \times 10^{-8} \mathrm{~m} / \mathrm{s}(\mathrm{G} 70)$ at $35^{\circ} \mathrm{C}$. We observe a 420 decrease in the mass transfer coefficient of diacetyl with the dry matter content of the solution. Nahon, 421 Harrison \& Roozen (2000) reported similar results within a range of 0 to $60 \% \mathrm{w} / \mathrm{w}$ of sucrose concentration.

423 Marin et al. (1999) measured a mass transfer coefficient for diacetyl at $35^{\circ} \mathrm{C}$ of $2 \times 10^{-6} \mathrm{~m} / \mathrm{s}$ for an 424 aqueous solution. Bakker et al. (1998) found a value of $2.7 \times 10^{-6} \mathrm{~m} / \mathrm{s}$ at $37^{\circ} \mathrm{C}$ for pure water and 425 showed that an increase in viscosity induced a decrease in the mass transfer coefficient, similarly to 426 our work.

\subsubsection{Physiological parameters}

430 In order to make the model as accurate as possible, all of the physiological parameters (except the 431 thickness of the product layer coating the pharynx) were measured for each panelist. The variation 432 ranges of the physiological parameters are presented in Table 3.

433 We observe that all physiological parameters present a wide range of variation. For example, the 434 volumes of oral cavity, nasal cavity and pharynx obtained by rhinopharyngometry are about $37 \pm 8$, $43511 \pm 4$ and $29 \pm 9 \mathrm{~cm}^{3}$, respectively. The contact areas in the oral cavity and the pharynx are $102 \pm 14 \mathrm{~cm}^{2}$ 436 and $60 \pm 13 \mathrm{~cm}^{2}$, respectively. 
440 We observed that the aroma release curve ("single repetition" curve in Fig. 2) has a sinusoidal shape, 441 and is synchronized with breath (data not shown): when a subject exhales, he/she brings aroma to 442 his/her nasal cavity (corresponding to the rising part of the sinusoid pattern), whereas during 443 inhalation, fresh air is delivered to the nose (decreasing part of the sinusoid pattern). We can also 444 observe that the first breath peak of the aroma release is the highest and corresponds to the delivery 445 that occurs immediately after the first swallow. The aroma concentration then gradually decreases, and 446 secondary peaks are due to the continuous aroma release induced by the flavored post-deglutitive film 447 coating the pharynx, which is permanently in contact with the breath airflow.

448 Figure 3 represents the mean peak curves of aroma release for the four solutions consumed by one 449 panelist. The global shapes of the kinetics are the same, regardless of the panelist or the product. 450 However, similarly to Buffo et al. (2005) and Linforth et al. (2000), we observed differences in 451 PTRMS responses for each subject due to their physiological characteristics. Nevertheless, G0 452 presents the highest intensity for the swallow-breath peak of aroma compound release for all panelists. 453 This observation was confirmed by a statistical analysis. Since our data were not normally distributed, 454 we performed a Friedman test (non parametric) with an excel macro developed by P. Georgin et M. 455 Gouet (available online at www.AnaStats.fr) on the in vivo release data, normalized by the initial 456 aroma concentration in the product, to see if we could observe a solution effect. The three analyzed 457 descriptors of the kinetics were: (1) the normalized area under the curve, (2) the normalized maximum 458 intensity $\mathrm{I}_{\mathrm{NAmax}} / \mathrm{C}_{\mathrm{OPini}}$ (first peak intensity), and (3) the decay time of the curve $\tau$. Results show that 459 there is a product effect on the first peak intensity (level of significance 0.05). Confirming the 460 empirical observation in Fig. 3, the classification performed with a multiple comparison test 461 (Bonferroni method with a macro developed by G. Le Page, available online at www.AnaStats.fr) 462 (Table 4) shows that the first diacetyl peak for flavored pure water (G0) is significantly higher than for 463 the other solutions (G40, G60 and G70) (level of significance 0.05).

464 The normalized area under the curve and the characteristic decay time of the curve were not 465 statistically different between the glucose syrup solutions. 


\subsection{Parameter effects on model predictions}

469

470

471

472

473

474

475

476

477

478

479

480

481

482

483

484

485

486

487

488

489

490

491

492

493

As mentioned in Section 2.1, the simplifications of the model were validated by comparing the kinetics obtained with the current model and the previous one with the same parameters. A sensitivity analysis of the new model was conducted.

We found that an increase in the mass transfer coefficient of the product induced an increase in the aroma concentration in the nasal cavity and a decrease in the characteristic decay time $\tau$.

The post-deglutitive residual thickness layer in the pharynx influences the characteristic decay time of the curve $\tau$. In fact, this time period follows the relationship:

$$
\tau \propto \frac{e}{k_{p}}
$$

where $e$ is the residual thickness layer in the pharynx and $\mathrm{k}_{\mathrm{p}}$ the mass transfer coefficient (Equation (15)). Moreover, this parameter has no influence on the height of the first aroma release peak. Last but not least, the lower the respiratory frequency is, the higher the aroma persistence will be.

\subsection{Comparison of model predictions with experimental data}

This section is dedicated to the comparison of model prediction with experimental data. Firstly, we verified that the aroma compound investigated in this study, i.e., diacetyl, does not specifically interact with the mucosa of the different compartments of the oro-pharyngeal sphere and the airways. Hodgson, Parker, Linforth \& Taylor (2004) stated that while volatile molecules are transferred through the upper airways, they absorb to the nasal mucosa. To check the absence of mucosa interaction, panelists were asked to absorb aroma compounds either in gaseous phase or in liquid phase, as described in the "Material and Methods" section. A typical result of each type of consumption protocol is illustrated in Fig. 4. On the one hand, we observe a curve for the liquid ingestion protocol (solid line) that shows secondary aroma release peaks due to persistence phenomena. On the other hand, the aroma release after inhaling the aroma compound in gaseous phase (dotted line) has only one major peak. This shows that no significant mucosa retention occurred. This is in agreement with the 
work of Normand et al. (2004), stating that short persistence of the aroma release (less than 1 min, which is the case in our study) is considered to be mainly due to saliva coating, whereas longer persistence is due to volatile adsorption in the mucosa. Therefore, introducing an additional mucosa compartment into the model was unnecessary for this aroma compound.

Secondly, another assumption of the model that was investigated was that complex airflow in the airways could have a significant effect on aroma kinetics. Tentatively, the model was implemented by considering an additional "lung" compartment and/or by subdividing the nasal cavity into several compartments, i.e., the nasal vestibule, the anterior turbinate and the posterior turbinate, with corresponding volumes and airflow fractions (Hahn, Scherer \& Mozell, 1993). It appeared that the effect of these additional compartments on model predictions was minor (results not shown). Therefore, we did not keep those compartments in the final version of the model.

Finally, two different hypotheses concerning the nature of the post-deglutitive residue coating the pharyngeal mucosa after swallowing were developed.

The first hypothesis assumed that a pure product layer is deposited on the pharyngeal mucosa. In this case, the air/product partition coefficients as well as the mass transfer coefficients are those obtained earlier in Section 3.1.

The second hypothesis assumed that the product coating the pharyngeal mucosa is highly diluted with saliva. In that case, the physico-chemical parameters of the bolus need to be recalculated according to the dilution rate.

These two hypotheses will be tested and discussed in the following sections.

\subsubsection{Assumption of the pure product layer $(\mathrm{H} 1)$}

By fitting the model to experimental data, we found a residual thickness layer in the pharynx of $14.6 \pm 3.4 \mu \mathrm{m}$ for $\mathrm{G} 0$, and of $2.9 \pm 1.1 \mu \mathrm{m}, 2.5 \pm 1 \mu \mathrm{m}$, and $0.8 \pm 0.2 \mu \mathrm{m}$ for $\mathrm{G} 40, \mathrm{G} 60$ and $\mathrm{G} 70$, respectively. In their work, Wright, Hills, Hollowood, Linforth \& Taylor (2003) found a thickness of film saliva (which is equivalent to our post-deglutitive residue) of $55 \mu \mathrm{m}$ for flavored aqueous 
521 solutions with only $2 \%$ of sucrose (which is close to our reference G0). Their thickness value is almost

522 four times higher than ours. This difference could result from individual variability or the 523 determination method used.

524 We then observed that similarly to in vivo measurements (Fig. 3), simulations predicted that the 525 highest peak intensity was reached for G0 (results not shown). The second set of bars in Fig. 5 shows 526 that the model prediction for the first aroma release peak for the aqueous solution is five times higher 527 than for the glucose syrup solutions. These differences are due to the differences that we found in the 528 mass transfer coefficients for the solutions studied. However, the in vivo data (first set of bars) do not 529 reveal such a large gap between the aqueous and the glucose syrup solutions (which reaches between $53058 \%$ and $83 \%$ of G0's Imax, depending on the solution and the panelist). These discrepancies between experimental observations and model predictions led us to consider that the product properties considered in the model (mass transfer and air/product partition coefficients) might be misevaluated 533 due to saliva dilution.

\subsubsection{Assumption of the product dilution by saliva $(\mathrm{H} 2)$}

536 Under the saliva dilution hypothesis, the aroma release profile of any glucose syrup solution predicted 537 by the model is expected to be closer to the reference solution (G0), as observed in vivo, because the 538 physico-chemical properties of the newly formed mixtures would be closer to the properties of water.

539 It is difficult to check this assumption in situ and, more specifically, to determine the quantity of saliva 540 present in the pharyngeal junction, as well as the amount of product left in the pharynx after 541 swallowing. Therefore, in order to validate this assumption, additional simulations were performed 542 and compared to in vivo data. Since the sensitivity analysis of the model showed that the residual 543 thickness layer does not have an impact on the first peak intensity of aroma release, we fixed this 544 parameter to the averaged value found for G0, i.e., $14.6 \mu \mathrm{m}$. After several tests, a common dilution 545 factor was determined for all solutions such that the model predictions fit the in vivo release data. 546 Physico-chemical parameters for dilutions not present in Table 2 were interpolated with the formulas indicated below Table 2 . 
548 The dilution factor was selected to keep the ratio "Intensity of the first peak for the investigated

549 solution"/“Intensity of the first peak for G0" as close as possible to in vivo experimental observations.

550 Results presented in Fig. 5 (first versus last series of bars in the chart) showed that it was possible to

551 find a common dilution factor that reproduces the intensity ratios observed in vivo.

552 Results indicated that all glucose syrup solutions were highly diluted in the pharynx (by a factor of $55310)$.

554 We validated the saliva dilution assumption with an additional aroma compound, ethyl hexanoate.

555 This molecule was chosen for its hydrophobicity, in contrast to diacetyl. Similarly to diacetyl, the 556 absence of retention by mucosa was checked. Since the two molecules were investigated together, we 557 performed simulations with the same residual thickness layer and with the same dilution factor that 558 was previously determined with diacetyl. Due to the introduction of the dilution factor, the physico559 chemical parameters of ethyl hexanoate in the glucose syrup solutions, G0, G5, G10 and G20, were

560 measured. On the basis of the results presented in Table 5, we can observe that the air/product 561 partition coefficient values for the three glucose syrup solutions are all higher than G0, but very close 562 to each other. For the mass transfer coefficient, we observe an opposite trend: the three glucose syrup 563 solutions values are lower than G0, but also close to each other. Similarly to the diacetyl, 564 interpolations of the experimental points were necessary to perform the simulations. For both the 565 air/product partition and mass transfer coefficients, we decided to use a linear regression between G0 566 and G5, and to calculate an averaged value between G5 and G20.

567 Comparison of the ratios "Intensity of the first peak for the investigated solution"/"Intensity of the first 568 peak for G0" between in vivo experiments and model predictions for ethyl hexanoate are presented in 569 Fig. 6. They show that the model provides a satisfactory prediction for all solutions under the saliva 570 dilution assumption, given the wide range of experimental variability (standard deviation bars on Fig. $5716)$.

573 These results lead to the conclusion that the viscosity of the initial product has a limited effect on 574 aroma release for products with Newtonian properties within the wide range of viscosities studied, and 575 confirm the results of Hollowood et al. (2002). The combined modeling and experimental approach 
conducted in this work suggests a possible explanation for this limited effect: viscous solutions are highly diluted by saliva during the swallowing step and the relevant properties are those of relatively similar product-saliva mixtures.

\subsection{Conclusions}

This work aimed at studying the influence of food viscosity on flavor release during ingestion of a liquid food. The originality of this study was the combination of experimental and modeling approaches that allowed us to gain insights into the aroma compound release mechanisms, based on the example of the diacetyl release from glucose syrup solutions. When considering the consumption of a liquid product, it can be assumed that the saliva dilution is relatively low due to the short residence time in the mouth. Therefore, the hypothesis that a pure product layer was deposited on the pharynx walls after ingestion of a liquid food was stated at first. This assumption was invalidated by the comparison of model predictions to in vivo measurements. This result led us to consider the dilution of the product during swallowing. This new hypothesis, stating that the film coating the pharyngeal walls was a mixture of saliva and product, provided predictions compatible with experimental observations for the aroma compound investigated (diacetyl). Simulations showed that

593 the dilution factors by saliva determined were quite similar, regardless of the initial dry matter of the

594 solution: approximately $10 \%$ of the initial solution was kept in the final diluted mixture. With these 595 dilution factors, we tentatively extended the model to a highly hydrophobic molecule (ethyl 596 hexanoate) with satisfactory results.

597 The formulated hypothesis has to be further confirmed based on the study of the release of other 598 aroma compounds with different physico-chemical characteristics. In parallel, work is in progress on 599 the pharynx mucosa coating to increase the understanding of these phenomena based on a mechanical 600 approach. Combining mechanical and mass transfer studies should help us to gain new insights into 601 the complex phenomena of in vivo aroma compound release. 


\section{Acknowledgements}

605 The authors gratefully acknowledge the French National Research Agency (ANR) project

606 "SensInMouth" for financial support.

607

608 
609

610

611

612

613

614

615

616

617

618

619

620

621

622

623

624

625

626

627

628

629

630

631

632

633

\section{$\underline{\text { References }}$}

Atlan, S., Trelea, I. C., Saint-Eve, A., Souchon, I. \& Latrille, E. (2006). Processing gas chromatographic data and confidence interval calculation for partition coefficients determined by the phase ratio variation method. Journal of Chromatography A, 1110(1-2), 146-155.

Bakker, J., Boudaud, N. \& Harrison, M. (1998). Dynamic release of diacetyl from liquid gelatin in the headspace. Journal of Agricultural and Food Chemistry, 46(7), 27142720 .

Buettner, A., Beer, A., Hannig, C. \& Settles, M. (2001). Observation of the swallowing process by application of videofluoroscopy and real-time magnetic resonance imaging-consequences for retronasal aroma stimulation. Chemical Senses, 26(9), 1211-1219.

Buffo, R. A., Rapp, J. A., Krick, T. \& Reineccius, G. A. (2005). Persistence of aroma compounds in human breath after consuming an aqueous model aroma mixture. Food Chemistry, 89(1), 103-108.

Cankurtaran, M., Celik, H., Coskun, M., Hizal, E. \& Cakmak, O. (2007). Acoustic rhinometry in healthy humans: Accuracy of area estimates and ability to quantify certain anatomic structures in the nasal cavity. Annals of Otology Rhinology and Laryngology, 116(12), 906-916.

Cheng, K. H., Cheng, Y. S., Yeh, H. C. \& Swift, D. L. (1997). Measurements of Airway Dimensions and Calculation of Mass Transfer Characteristics of the Human Oral Passage. Journal of Biomechanical Engineering, 119(4), 476-482.

Collins, L. M. C. \& Dawes, C. (1987). The Surface Area of the Adult Human Mouth and Thickness of the Salivary Film Covering the Teeth and Oral Mucosa. Journal of dental research, 66(8), 1300-1302. 
634 Cook, D. J., Hollowood, T. A., Linforth, R. S. T. \& Taylor, A. J. (2003). Oral shear stress predicts flavour perception in viscous solutions. Chemical Senses, 28(1), 11-23.

636 Cussler, E. L. (1997). Diffusion: Mass Transfer in Fluid Systems. (2ème édition ed.). Cambridge: University Press.

Dawes, C. (2008). Salivary flow patterns and the health of hard and soft oral tissues. $J \mathrm{Am}$ Dent Assoc, 139 Suppl, 18S-24S.

640 Elert, G. (2009). Volume of Human Lungs. In).

641 Engelen, L., de Wijk, R. A., Prinz, J. F., van der Bilt, A. \& Bosman, F. (2003). The relation between saliva flow after different stimulations and the perception of flavor and texture attributes in custard desserts. Physiology \& Behavior, 78(1), 165-169.

644 Ettre, L., Welter, C. \& Kolb, B. (1993). Determination of gas-liquid partition coefficients by 645 automatic equilibrium headspace-gas chromatography utilizing the phase ratio variation method. Chromatographia, 35(1), 73-84.

Friel, E. N., Linforth, R. S. T. \& Taylor, A. J. (2000). An empirical model to predict the headspace concentration of volatile compounds above solutions containing sucrose. Food Chemistry, 71, 309-317.

Hahn, I., Scherer, P. W. \& Mozell, M. M. (1993). Velocity profiles measured for airflow through a large-scale model of the human nasal cavity. J Appl Physiol, 75(5), 22732287.

Hodgson, M., Langridge, J. P., Linforth, R. S. T. \& Taylor, A. J. (2005). Aroma release and delivery following the consumption of beverages. Journal of Agricultural and Food Chemistry, 53(5), 1700-1706.

Hodgson, M., Parker, A., Linforth, R. S. \& Taylor, A. J. (2004). In vivo studies on the long657 term persistence of volatiles in the breath. Flavour and Fragrance Journal, 19(6), 470-475. 
Hollowood, T. A., Linforth, R. S. T. \& Taylor, A. J. (2002). The effect of viscosity on the perception of flavour. Chemical Senses, 27(7), 583-591.

Kora, E. P., Souchon, I., Latrille, E., Martin, N. \& Marin, M. (2004). Composition rather than viscosity modifies the aroma compound retention of flavored stirred yogurt. Journal of Agricultural and Food Chemistry, 52(10), 3048-3056.

Lauverjat, C., de Loubens, C., Deleris, I., Trelea, I. C. \& Souchon, I. (2009). Rapid determination of partition and diffusion properties for salt and aroma compounds in complex food matrices. Journal of Food Engineering, 93(4), 407-415.

Linforth, R. \& Taylor, A. J. (2000). Persistence of Volatile Compounds in the Breath after Their Consumption in Aqueous Solutions. Journal of Agricultural and Food Chemistry, 48(11), 5419-5423.

Marieb, E. N. \& Hoehn , K. (2008). Human Anatomy \& Physiology (7th ed.): BenjaminCummings Publishing Company.

Marin, M., Baek, I. \& Taylor, A. J. (1999). Volatile Release from Aqueous Solutions under Dynamic Headspace Dilution Conditions. Journal of Agricultural and Food Chemistry, 47(11), 4750-4755.

Menache, M. G., Hanna, L. M., Gross, E. A., Lou, S. R., Zinreich, S. J., Leopold, D. A., Jarabek, A. M. \& Miller, F. J. (1997). Upper respiratory tract surface areas and volumes of laboratory animals and humans: Considerations for dosimetry models. Journal of Toxicology and Environmental Health, 50(5), 475-506.

Nahon, D. F., Harrison, M. \& Roozen, J. P. (2000). Modeling Flavor Release from Aqueous Sucrose Solutions, Using Mass Transfer and Partition Coefficients. Journal of Agricultural and Food Chemistry, 48(4), 1278-1284. 
682 Nahon, D. F., Koren, P., Roozen, J. P. \& Posthumus, M. A. (1998). Flavor release from

683

684

685

686

687

688

689

690

691

692

693

694

695

696

697

698

699

700

701

702

703

704

705 mixtures of sodium cyclamate, sucrose, and an orange aroma. Journal of Agricultural and Food Chemistry, 46(12), 4963-4968.

Nawar, W. W. (1971). Some variables affecting composition of headspace aroma. Journal of Agricultural and Food Chemistry: 19 (6) 1057-1059, 19(6), 1057-1059.

Normand, V., Avison, S. \& Parker, A. (2004). Modeling the kinetics of flavour release during drinking. Chemical Senses, 29(3), 235-245.

Palsson, B., Hubbell, J. A. \& Plonsey, R. (2003). Tissue Engineering CRC Press.

Saint-Eve, A., Martin, N., Guillemin, H., Semon, E., Guichard, E. \& Souchon, I. (2006). Flavored yogurt complex viscosity influences real-time aroma release in the mouth and sensory properties. Journal of Agricultural and Food Chemistry, 54(20), 77947803.

Sherwood, L. (2006). Fundamentals of Physiology: A Human Perspective (p.380): Thomson Brooks/Cole.

Thanh, M. L., Thibeaudeau, P., Thibaut, M. A. \& Voilley, A. (1992). Interactions between volatile and non-volatile compounds in the presence of water. Food Chemistry: 43 (2) 129-135, 43(2), 129-135.

Tortora, G. J. \& Anagnostakos, N. P. (1990). Principles of Anatomy and Physiology (p. 707) (6th edition ed.): New York: Harper-Collins.

Trelea, I. C., Atlan, S., Deleris, I., Saint-Eve, A., Marin, M. \& Souchon, I. (2008). Mechanistic mathematical model for in vivo aroma release during eating of semiliquid foods. Chemical Senses, 33(2), 181-192.

Weel, K. G. C., Boelrijk, A. E. M., Burger, J. J., Verschueren, M., Gruppen, H., Voragen, A. G. J. \& Smit, G. (2004). New device to simulate swallowing and in vivo aroma release 
in the throat from liquid and semiliquid food systems. Journal of Agricultural and Food Chemistry, 52(21), 6564-6571.

708 Wen, J., Inthavong, K., Tu, J. \& Wang, S. M. (2008). Numerical simulations for detailed airflow dynamics in a human nasal cavity. Respiratory Physiology \& Neurobiology, 161(2), 125-135.

Wright, K. M. \& Hills, B. P. (2003). Modelling flavour release from a chewed bolus in the mouth: Part II. The release kinetics. International Journal of Food Science \& Technology, 38, 361-368.

714 Wright, K. M., Hills, B. P., Hollowood, T. A., Linforth, R. S. T. \& Taylor, A. J. (2003). Persistence effects in flavour release from liquids in the mouth. International Journal of Food Science \& Technology, 38(3), 343-350.

Xue, S. A. \& Hao, J. P. G. (2006). Normative standards for vocal tract dimensions by race as measured by acoustic pharyngometry. Journal of Voice, 20(3), 391-400. 


\section{Figure legends}

724

725

726

727

728

729

730

Figure 6. "Imax of a solution/Imax of G0" ratios for ethyl hexanoate: comparison of experimental data 745

Figure 1. A. Schematic representation of the nasal cavity, pharynx and oral cavity as interconnected reactors. B. Chronological steps of the consumption of a semi-liquid food.

Figure 2. Example of data processing for in vivo aroma release experiments (solution G0, with 16.5mg/L of diacetyl). Dotted line: diacetyl intensity signal recorded by PTR-MS. For clarity, only one single replicate is shown. Solid line: peak curve of the shown replicate. Bold line: mean of the three peak curves for the three replicates of the experiment. Gray area: envelope of the peak curves for the three replicates.

Figure 3. Example of in vivo diacetyl release for the four Newtonian solutions (panelist 1). Representation of the mean peak curves.

Figure 4. Example of in vivo diacetyl release during two consumption protocols. Solid line: ingestion of aromatized solution; dotted line: aspiration of aromatized air.

Figure 5. "Imax of a solution/Imax of G0" ratios for diacetyl: comparison of experimental data with the model simulations under the "pure product layer (H1)" and the "saliva dilution (H2)" assumptions. with the model simulations under the "saliva dilution (H2)" assumption. 


\section{$747 \quad$ Tables}

748

749 Table 1. Characteristics of the analyzed glucose syrup solutions.

750

\begin{tabular}{ccc}
\hline Solutions & Dry Matter (g/100g) & Viscosity at $\mathbf{3 5}^{\circ} \mathbf{C}(\mathbf{m P a} \mathbf{s})$ \\
\hline G0 & 0.00 & 0.7 \\
G5 & $5.13 \pm 0.19$ & 0.8 \\
G10 & $8.99 \pm 0.30$ & 1.1 \\
G20 & $20.19 \pm 0.73$ & 1.5 \\
G40 & $45.94 \pm 1.70$ & 7.6 \\
G60 & $61.11 \pm 1.19$ & 25.0 \\
G70 & $75.68 \pm 2.65$ & 405.0 \\
\hline
\end{tabular}

751

752

753 
754 Table 2. Diacetyl air/product partition coefficient $\left(\mathrm{K}_{\mathrm{ap}}\right)$ and mass transfer coefficient $\left(\mathrm{k}_{\mathrm{p}}\right)$ as a function 755 of the dry matter content for Newtonian glucose syrup solutions at $35^{\circ} \mathrm{C}$.

756

\begin{tabular}{ccc}
\hline Solutions & $\mathbf{K}_{\text {ap }}(\mathbf{g} / \mathbf{g})^{\dagger}$ & $\mathbf{K}_{\mathbf{p}}(\mathbf{m} / \mathbf{s})^{\ddagger}$ \\
$\mathbf{x} 10^{-4}$ & $\times 10^{-7}$ \\
\hline G0 & $12.84 \pm 3.11$ & $11.03 \pm 3.9$ \\
G5 & $5.72 \pm 2.21$ & $4.26 \pm 2.18$ \\
G10 & $6.78 \pm 3.27$ & $4.50 \pm 2.85$ \\
G20 & $4.59 \pm 3.97$ & $2.50 \pm 2.48$ \\
G40 & $7.88 \pm 4.37$ & $1.94 \pm 1.34$ \\
G60 & $11.69 \pm 4.28$ & $1.24 \pm 0.48$ \\
G70 & $25.12 \pm 4.97$ & $0.33 \pm 0.07$ \\
\hline
\end{tabular}

757

$758 \uparrow$ For G10, G20, G60, 3 replicates were performed. For G0, G5, G30, G40 and G70, 6 replicates were 759 performed

$760 \quad$ Between 3 and 9 replicates were preformed for each solution

761 For Diacetyl air/product partition coefficient $\left(\mathrm{K}_{\mathrm{ap}}\right)$, the following second-degree polynomial regression 762 curve fits the data $\left(\mathrm{R}^{2}=0.94\right)$ and was used for interpolation:

$$
K_{a p}=8.69 \times 10^{-7} \times C_{g}^{2}-5.036 \times 10^{-5} \times C_{g}+10.55 \times 10^{-4}
$$

764 where $\mathrm{C}_{\mathrm{g}}$ is the total carbohydrate concentration in $\mathrm{g} / 100 \mathrm{~g}$.

765 For Diacetyl mass transfer coefficient $\left(k_{p}\right)$, the following non-linear regression (exponential type) fits 766 the data $\left(\mathrm{R}^{2}=0.88\right)$ and was used for interpolation:

$$
\log \left(k_{p}\right)=-6.1549-0.0367 \times C_{g}
$$

768 where $\mathrm{Cg}$ is the total carbohydrate concentration in $\mathrm{g} / 100 \mathrm{~g}$.

769 Error bars on the mass transfer coefficient take into account the uncertainties of the air/solution 770 partition coefficients. 


\begin{tabular}{|c|c|c|c|c|c|}
\hline & Unit & $\begin{array}{c}\text { Mean } \\
\text { value/range } \\
\text { of } \\
\text { variation } \\
\end{array}$ & Data source & Reference & $\begin{array}{l}\text { Value from the } \\
\text { literature }\end{array}$ \\
\hline $\begin{array}{l}\text { Oral cavity } \\
\text { Volume }\end{array}$ & $\mathrm{cm}^{3}$ & $30-45$ & Rhinopharyngometry & (Xue \& Hao, 2006) & $32.95 \pm 6.10$ \\
\hline $\begin{array}{l}\text { Nasal cavity } \\
\text { volume }\end{array}$ & $\mathrm{cm}^{3}$ & $4-14$ & Rhinopharyngometry & $\begin{array}{l}\text { (Cankurtaran, Celik, } \\
\text { Coskun, Hizal \& } \\
\text { Cakmak, 2007) }\end{array}$ & $9.11 \pm 0.71^{\ddagger}$ \\
\hline $\begin{array}{l}\text { Pharynx } \\
\text { volume }\end{array}$ & $\mathrm{cm}^{3}$ & $20-45$ & Rhinopharyngometry & (Xue \& Hao, 2006) & $29.65 \pm 6.10$ \\
\hline $\begin{array}{l}\text { Residual } \\
\text { product } \\
\text { thickness in } \\
\text { the pharynx }\end{array}$ & $\mu \mathrm{m}$ & $0.8-14.6$ & $\begin{array}{c}\text { Degree of freedom of } \\
\text { the model } \\
\text { (case of the pure } \\
\text { product layer } \\
\text { hypothesis) }\end{array}$ & $\begin{array}{c}\text { (Wright \& Hills, } \\
\text { 2003) }\end{array}$ & $55 \times 10^{-3}$ \\
\hline $\begin{array}{l}\text { Salivary } \\
\text { flow rate }\end{array}$ & $\mathrm{cm}^{3} / \mathrm{s}$ & $\begin{array}{l}3 \times 10^{-2}- \\
4.7 \times 10^{-2}\end{array}$ & $\begin{array}{c}\text { Standard protocol } \\
\text { (parafilm stimulation) }\end{array}$ & $\begin{array}{l}\text { (Engelen, de Wijk, } \\
\text { Prinz, van der Bilt \& } \\
\text { Bosman, 2003) } \\
\text { (Dawes, 2008) }\end{array}$ & $\begin{array}{c}\text { Less than } 3.3 \times 10^{-2} \mathrm{~cm}^{3} / \mathrm{s} \\
1.5 \times 10^{-2}-2.2 \times 10^{-2} \mathrm{~cm}^{3} / \mathrm{s} \\
\text { (parafilm stimulation) }\end{array}$ \\
\hline $\begin{array}{l}\text { In-mouth } \\
\text { saliva } \\
\text { volume }\end{array}$ & $\mathrm{cm}^{3}$ & 1.1 & Literature & (Dawes, 2008) & $\begin{array}{c}\text { 1.1/0.8 (before/after } \\
\text { swallowing) }\end{array}$ \\
\hline $\begin{array}{l}\text { In-mouth } \\
\text { air/product } \\
\text { contact area }\end{array}$ & $\mathrm{cm}^{2}$ & $81-120$ & $\begin{array}{c}\text { Calculated } \\
\text { (Appendix A) }\end{array}$ & $\begin{array}{c}\text { (Collins \& Dawes, } \\
\text { 1987) }\end{array}$ & $214.7 \pm 12.9$ \\
\hline $\begin{array}{l}\text { Pharynx } \\
\text { air/product } \\
\text { contact area }\end{array}$ & $\mathrm{cm}^{2}$ & $54-81$ & $\begin{array}{c}\text { Calculated } \\
\text { (Appendix A) }\end{array}$ & $\begin{array}{l}\text { (Normand, Avison \& } \\
\quad \text { Parker, 2004) }\end{array}$ & 33 \\
\hline $\begin{array}{l}\text { Tidal } \\
\text { volume }\end{array}$ & $\mathrm{cm}^{3}$ & $470-1460$ & Spirometry & $\begin{array}{l}\text { (Palsson, Hubbell \& } \\
\text { Plonsey, 2003) } \\
\text { (Elert, 2009) }\end{array}$ & $390-500$ \\
\hline $\begin{array}{l}\text { Respiratory } \\
\text { frequency }\end{array}$ & $\begin{array}{l}\text { Number } \\
\text { of } \\
\text { cycles/ } \\
\text { min }\end{array}$ & $11.5-19.5$ & $\begin{array}{c}\text { Ion } 59 \text { signal (PTR- } \\
\text { MS) }\end{array}$ & $\begin{array}{c}\text { (Tortora \& } \\
\text { Anagnostakos, 1990) } \\
\text { (Sherwood, 2006) } \\
\text { (Marieb \& Hoehn } \\
\text { 2008) }\end{array}$ & $12-20$ \\
\hline
\end{tabular}

\footnotetext{
$\dagger$ Values of parameters measured for panelists

$\$$ sum of the volumes of the nasal valve, the lower and the middle turbinate
} 
777 Table 4. Statistical analysis of in vivo diacetyl release curves

778

\begin{tabular}{cc}
\hline Solutions & $\mathbf{I}_{\text {NAmax }} / \mathbf{C}_{\text {OPini }}\left(\mathbf{1 0}^{\mathbf{5}} \mathbf{c p s} / \mathbf{p p b}\right)$ \\
\hline G0 & $1.53 \mathrm{~A}$ \\
$\mathbf{G 4 0}$ & $1.24 \mathrm{AB}$ \\
$\mathbf{G 6 0}$ & $0.99 \mathrm{~B}$ \\
$\mathbf{G 7 0}$ & $0.85 \mathrm{~B}$ \\
\hline
\end{tabular}

779

780 Each letter corresponds to a classification group performed with Bonferroni method (significance 781 level=0.05).

782 
784 Table 5. Physicochemical characteristics of glucose syrup solutions aromatized with ethyl hexanoate 785

\begin{tabular}{ccc}
\hline Solutions & $\begin{array}{c}\text { Air/product partition } \\
\text { coefficient }(\mathrm{g} / \mathbf{g})\end{array}$ & $\begin{array}{c}\text { Mass transfer } \\
\text { coefficient }(\mathbf{m} / \mathbf{s})\end{array}$ \\
& $\times 10^{-1}$ & $\mathrm{x} 10^{-6}$ \\
\hline G0 & $0.82 \pm 0.17$ & $8.74 \pm 1.63$ \\
G5 & $1.30 \pm 0.51$ & $5.46 \pm 1.84$ \\
G10 & $1.22 \pm 0.30$ & $4.27 \pm 0.75$ \\
G20 & $1.33 \pm 0.56$ & $5.29 \pm 2.07$ \\
\hline
\end{tabular}

786

787 


\section{APPENDIX A}

\section{Calculation of the area of the mouth and the pharynx}

791

792

793

794

795

796

797

798

799

800

801

802

803

804

805

806

807

808

809

810

811

$$
\text { Area }=\sum \text { Perimeter }(h) \Delta h
$$

where $d h$ is the distance between two successive measurements of cross-sectional areas with the rhinopharyngometer $(0.43 \mathrm{~cm})$.

and:

$$
\operatorname{Perimeter}(h)=\pi \times[3 \times(a+b)-\sqrt{(3 a+b) \times(a+3 b)}]
$$

$$
S=\pi \times a \times b
$$

where $S$ is the cross-sectional area measured at a given distance, $a$ the major radius and $b$ the minor radius.

Given $k=\frac{a}{b}$ as the ratio between the two radii, we obtain:

$$
a=\sqrt{\frac{S \times k}{\pi}}
$$

where $\mathrm{k}=7.4$ for the mouth, 1.25 for the oropharynx and 1 for the hypopharynx.

The total area of a compartment is therefore the sum of all intermediate areas that have been calculated within the limit of the compartment considered. 


\section{APPENDIX B}

\section{Model for the determination of the Mass Transfer Coefficient}

815 In the Volatile Air Stripping Kinetic (VASK) method (Lauverjat, de Loubens, Deleris, Trelea \&

816 Souchon, 2009), the product containing the volatile compound is equilibrated with the headspace air in

817 a closed flask. At time $\mathrm{t}=0$, the headspace is stripped with a constant airflow, and the volatile

818 compound concentration in the outlet air is continuously measured by PTR-MS.

819 The volatile concentrations in the product and in the headspace are given by:

$$
V_{p} \times \frac{d C_{p}}{d t}=-A \times k_{p} \times\left(C_{p}-\frac{C_{a}}{K_{a p}}\right)
$$

$$
V_{a} \times \frac{d C_{a}}{d t}=A \times k_{p} \times\left(C_{p}-\frac{C_{a}}{K_{a p}}\right)-C_{a} \times Q
$$

822 where:

$823 V_{p}$ and $V_{a}$ are the volume of the liquid product and of the air, respectively.

$824 \quad \mathrm{~A}$ is the contact area between the air and the product.

$825 \mathrm{Q}$ is the air flow rate stripping the headspace.

$826 C_{p}$ and $C_{a}$ are the concentration of aroma in the product and in the air, respectively.

827 The mass transfer coefficient $\left(\mathrm{k}_{\mathrm{p}}\right)$ is determined by fitting the air concentration predicted by 828 the model to the PTR-MS measurements. 


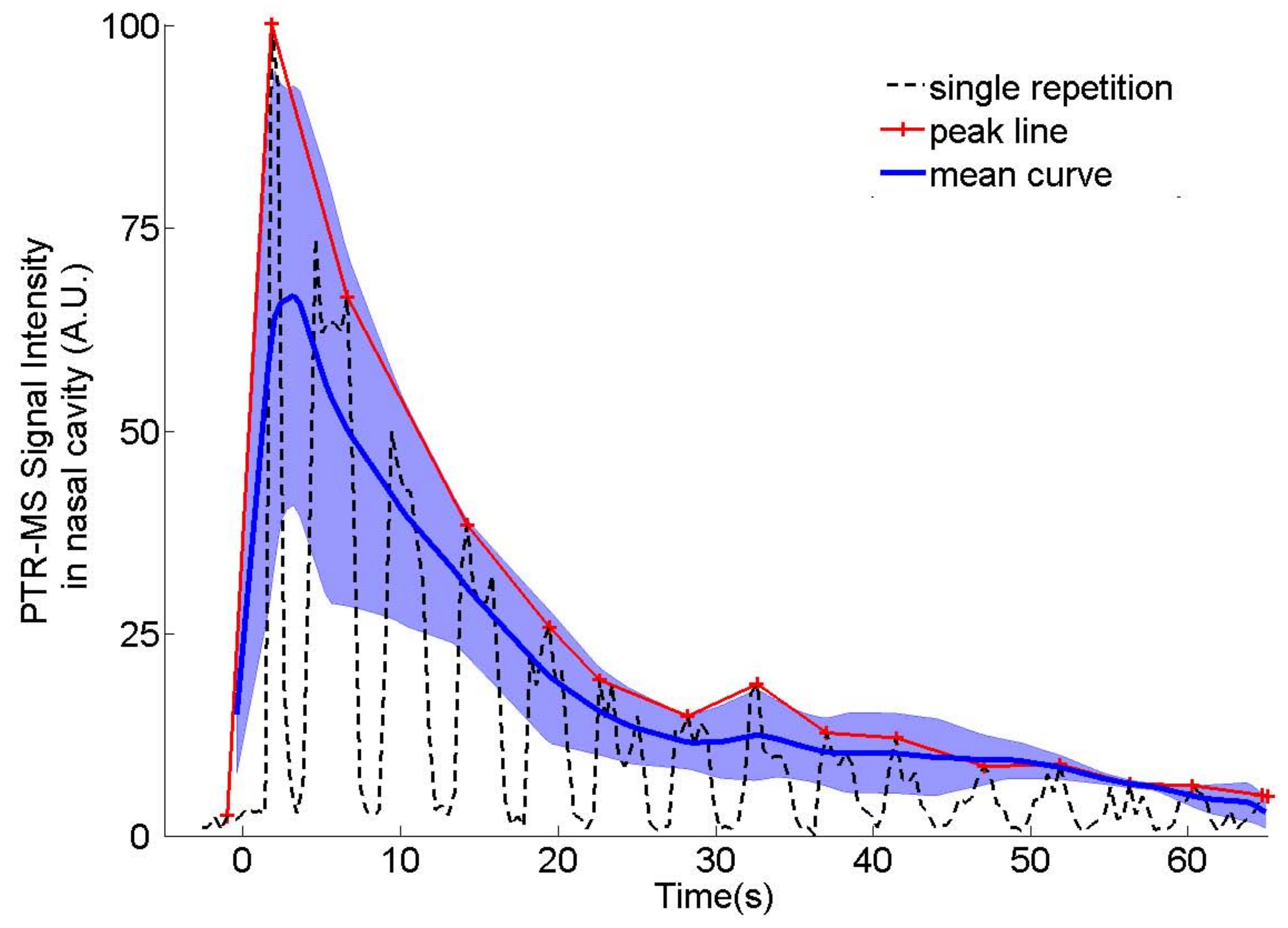




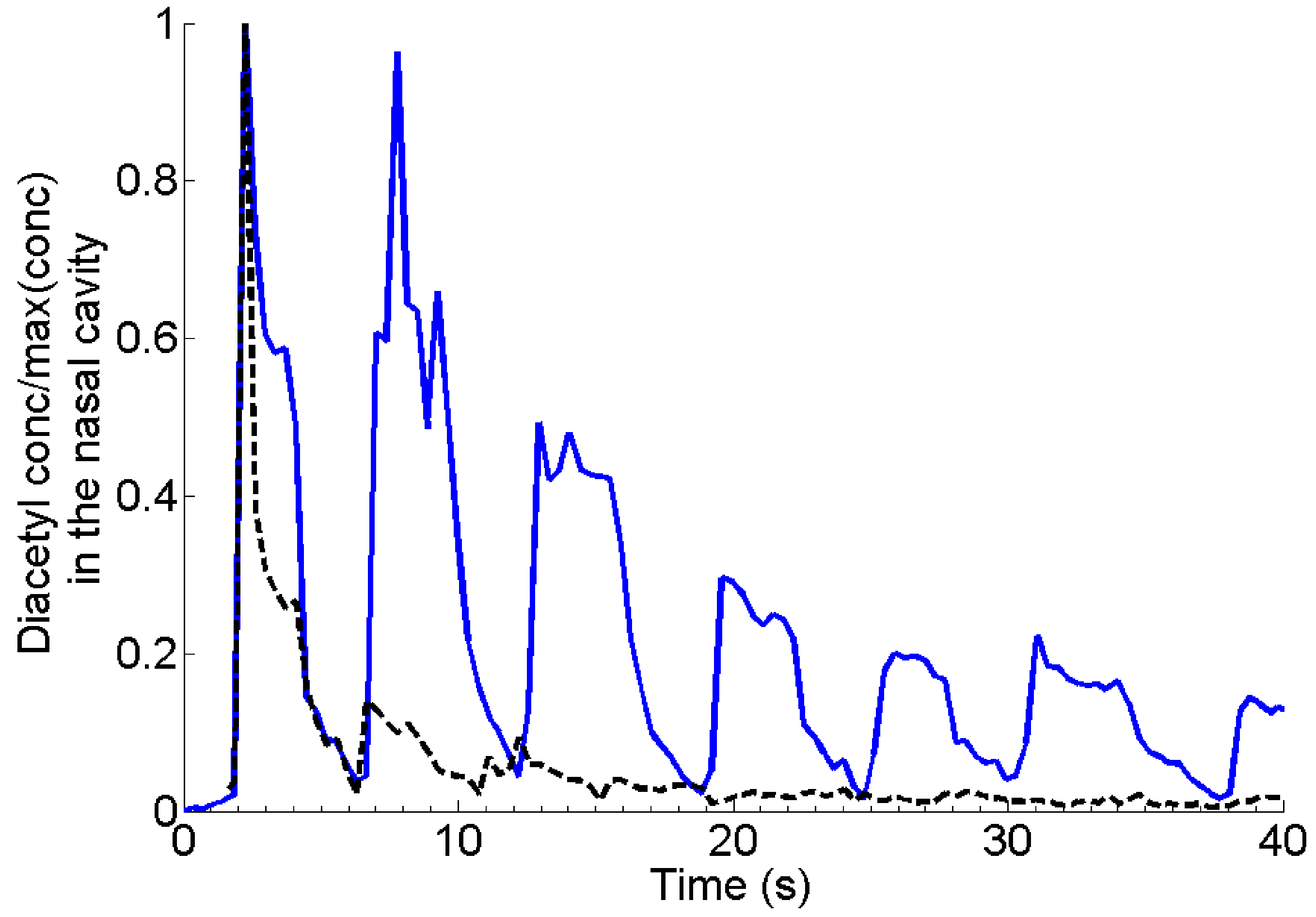




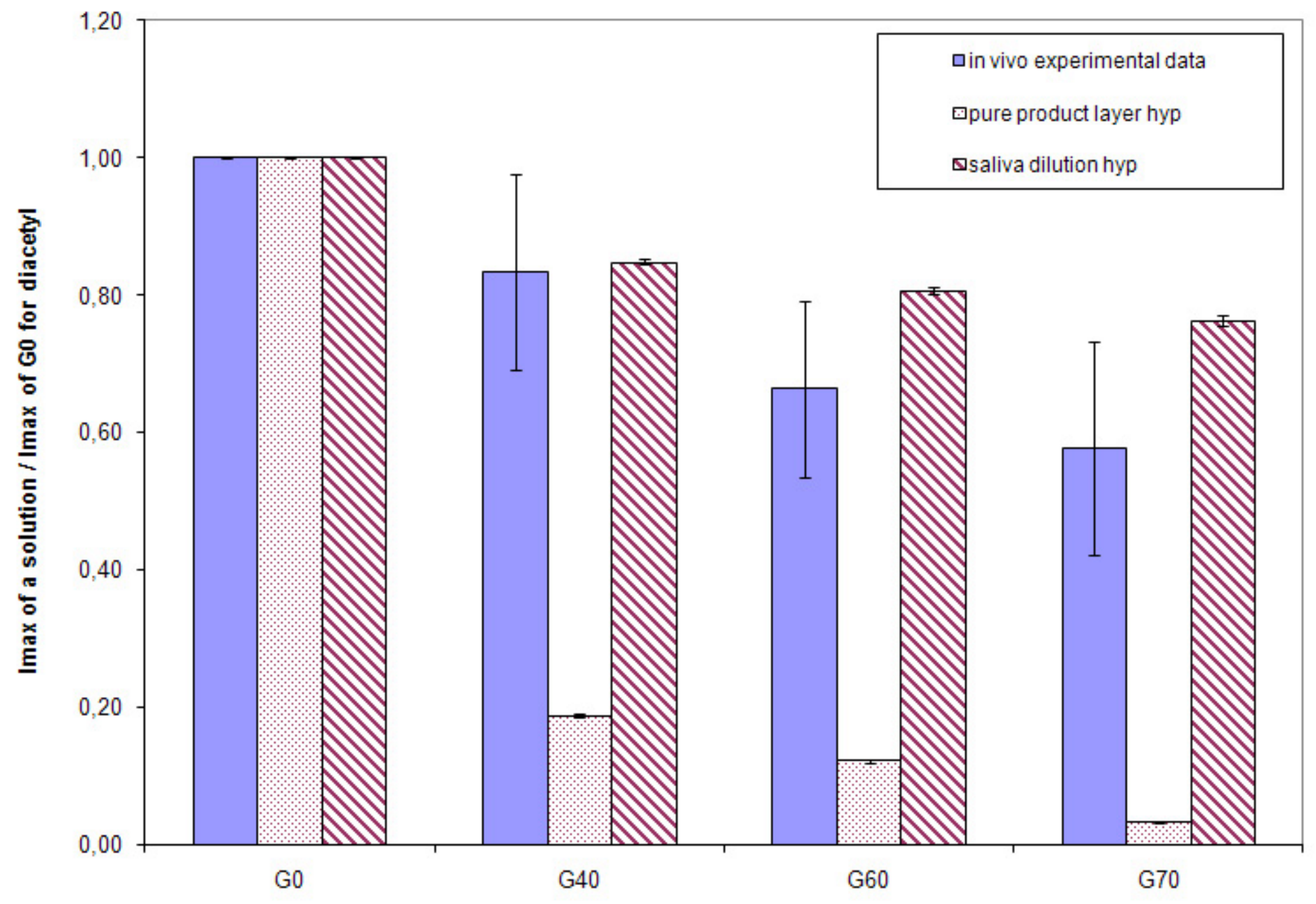




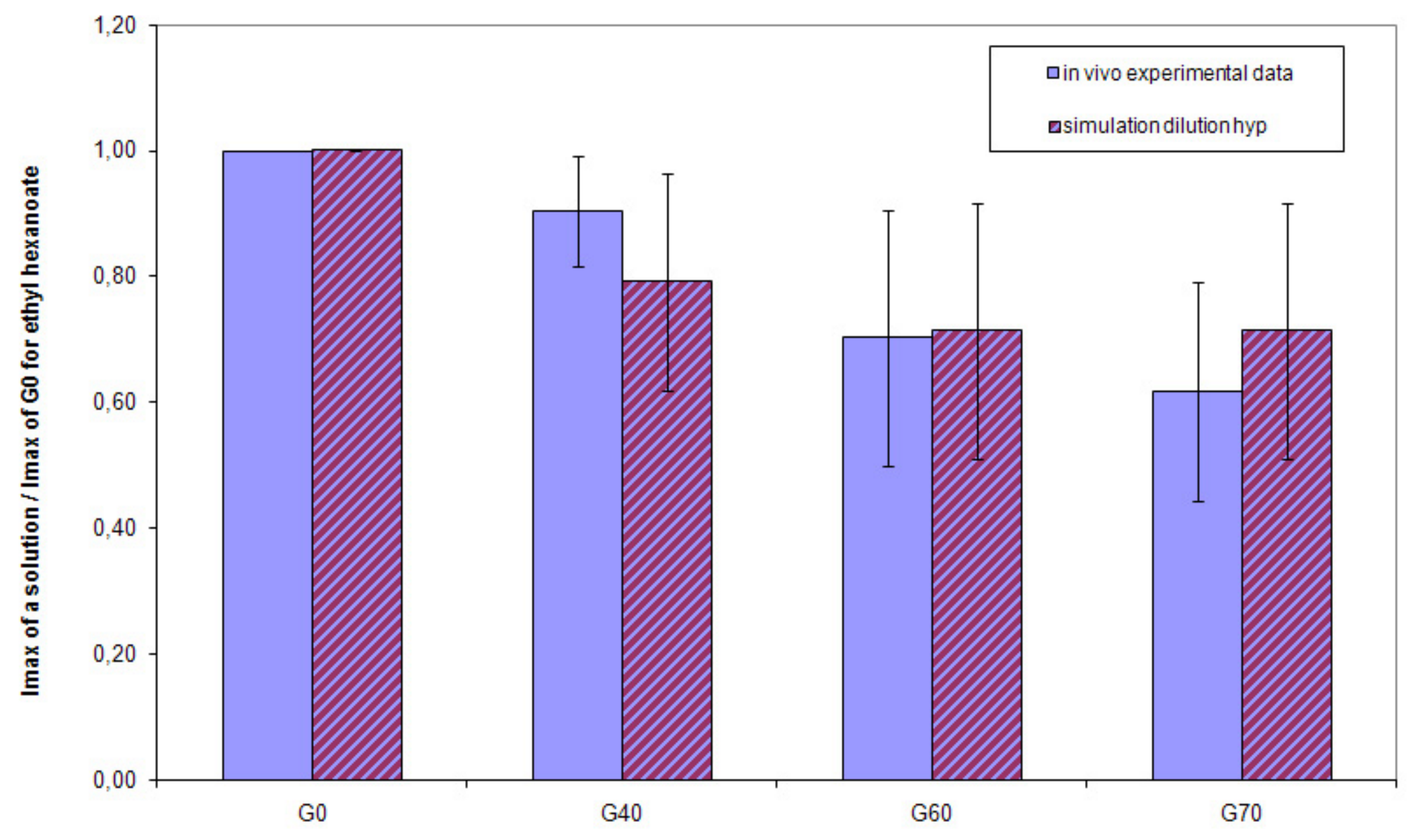

